\title{
Business retention and expansion (BRE) today - research, application, and evaluation: Introduction to the special issue
}

by Michael Darger, University of Minnesota Extension Center for Community Vitality 462 Coffey Hall, 1420 Eckles Ave., St. Paul, MN 55108, darger@umn.edu

Alan Barefield, Mississippi State University Dept. of Agricultural Economics, 371-B Lloyd Ricks, Mississippi State, MS 39762, alan.barefield@msstate.edu

Brent D. Hales, University of Minnesota Extension, 240 Coffey Hall, 1420 Eckles Ave., St. Paul, MN 55108,BDHales@umn.edu

\section{The Version of Record of this manuscript has been published and is available in Community Development, January 18, 2017, http://www.tandfonline.com/ http://dx.doi.org/10.1080/15575330.2017.1285334.}

\begin{abstract}
Business retention and expansion (BRE) has existed as a formal activity for economic development since the 1980s. BRE is one of the most prevalent activities within the field of economic development. This special issue includes research, program evaluation, and case studies demonstrating the diverse ways that economic development organizations are reaching out and responding to existing businesses. The contributed articles examine several important BRE topics. Some authors took a more theoretical approach by investigating survey datasets from large professional associations, and others contributed practitioner stories of BRE innovations. Still others shared the results and evolution of state/provincial programs. A focused literature review was conducted by the guest editors on a set of relevant topics not covered in the contributed articles. This special issue is a collection of literature contributing to both BRE theory and practice, yet there are continuing gaps in our collective knowledge that merit future research and discussion.
\end{abstract}

Keywords: BRE; business retention and expansion; business visitation; economic development 
This special issue explores economic development activities and methodologies targeted to businesses that already exist in a community or region. These activities and methodologies have come to be collectively known as business retention and expansion (BRE). BRE has formally existed as a central activity and priority for economic development practitioners for at least three decades, with roots going back to the 1960s and 1970s (Morse, 1990; Loveridge \& Smith, 1992). A wide variety of public and private organizations in communities, regions, and states/provinces in North America and beyond have incorporated BRE programming into their community economic development programs (Warner \& Zheng, 2011; Zhang \& Warner, 2017; Oosterbaan \& Morris, 2017). A 2009 national survey in the US found that $62 \%$ of cities and counties were doing BRE surveys with their businesses and $82 \%$ were partnering with chambers of commerce or others on BRE (Warner \& Zheng, 2011). Business Retention and Expansion International (BREI) has existed as an association for BRE professionals for over 20 years to promote best practices and build capacity through education. The International Economic Development Council (IEDC) also offers BRE education and finds that "Surveys of U.S. economic development organizations rank it (BRE) as the number one economic development activity” (IEDC, 2016, p. 4). However, before this special issue of Community Development focused on BRE, there has not been any organized collection of academic or practitioner literature on BRE since George Morse's book The Retention and Expansion of Existing Businesses - Theory and Practice in Business Visitation Programs (1990).

\section{What is business retention and expansion?}

Morse defined BRE "as all those local development efforts that are aimed at facilitating and encouraging the growth of existing businesses” (1990, p. 15). BRE programs have evolved from loose-knit, informal efforts in the 1960s and 1970s, developing into organized, formal programs 
in the 1980s. Although he prioritized expansion and retention of local firms in his conceptual model, Morse also connected the importance of BRE programs in providing data useful for local business attraction efforts (1990).

From the perspective of state economic development entities, Bradshaw and Blakely (1999) describe three waves of economic development. The first wave "was dominated by programs designed specifically to attract footloose firms from old industrial areas to growing regions" (1999, p. 230). The second wave "shifted focus from attracting out-of-state firms to retaining and expanding existing firms” (1999, p. 230). The authors’ research with 15 state economic development agencies showed an overwhelming preference for BRE efforts over 11 other priorities. They suggest that BRE programs are fundamental in developing regional clusters and a robust industrial core as states move to a third wave where they target specific industries through industrial policy. Both Morse and Bradshaw and Blakely talk about the shift from firmlevel attraction to increased emphasis on working with the firms already existing in a jurisdiction. Further, they point to the BRE opportunity to identify and work on systemic issues that affect multiple firms as opposed to the focus on individual firms in business attraction strategies (Morse, 1990; Bradshaw \& Blakely, 1999).

BRE today is a mix of methods, tools, and players. In its narrowest sense, BRE involves outreach efforts by an economic development organization (EDO) to understand the needs, concerns, and aspirations of businesses in a service area. Traditionally, this has occurred through in-person survey interviews to gather data and establish rapport with business owners or managers. The challenge for the EDO is to respond in an effective manner to both individual business issues and to more systemic issues affecting multiple businesses. 
In the 1980s and 1990s there were concentrated efforts by states, provinces, and universities to organize discrete, volunteer visitor based, BRE visitation programs at the local level (Coleman, 1991; Loveridge \& Smith, 1992; Loveridge \& Morse, 1998; Darger, Tuck, \& Bennett, 2017; Oosterbaan \& Morris, 2017). Features of this approach include all-at-once visits over a period of one to two months for a two-fold purpose: to respond to individual firm concerns and to identify systemic issues that affect multiple businesses. While volunteer visitor BRE continues in some places, it is the consensus of the guest editors that the majority of BRE users in the field today employ a continuous visitation approach. This continuous approach features EDO professionals working individually or with selected board members and/or stakeholders to visit local businesses throughout the year. The EDOs use various tools at their disposal to respond to business needs in the continuous approach. They may or may not concern themselves with more systemic issues.

Contemporary BRE methods and tools have proliferated to include electronic surveys, mobile-based survey tools (i.e. for tablet computers or even smart phones), conversational approaches, focus groups and other qualitative methods, and both more formal and less formal methods of outreach. Many EDOs choose to use specialized software packages available from industry consultants. These more advanced systems are typically used by larger cities and by regional entities that desire a consistent platform. On the other hand, many EDOs continue to use generic CRM (customer relationship management) systems and other off-the-shelf tools or develop a process that they believe is a cost effective answer to identifying opportunities and threats to existing businesses. As previously mentioned, BRE-focused courses are available from several entities. 


\section{Articles in this special issue}

This special issue describes the context of modern BRE practice and its role within the economic development field. It addresses several themes and was developed with contributions from both academic researchers and practitioner-scholars in the economic development field. Contributing authors included campus-based research faculty, Extension educators (i.e. land grant university professionals affiliated with the US Cooperative Extension Service), and economic development practitioners from both the public and the private sectors. Authors contributed articles in three basic categories: research, program evaluation and development, and case studies.

Research articles:

- Retention of rural businesses as baby boomer owners retire (Templin et al., 2017)

- The interface of BRE with business clusters (Zhang \& Warner, 2017)

- How economic developers are defining success in BRE (Morgan \& Morphis, 2017).

Program evaluation and development articles:

- State Extension program working with communities (Darger, Tuck, \& Bennett, 2017)

- State chamber of commerce partnering with local chambers (O’Neil, Riffe, \& Schaff, 2017)

- Canadian province’s work in rural BRE programming (Oosterbaan \& Morris, 2017).

Case study articles:

- Innovating with energy efficiency investments and BRE (Bowen-Ellzey \& Romich, 2017)

- Entrepreneurship approach in a major urban area (Warren, 2017) 
- Using BRE techniques with a state transportation agency (Munnich \& Douma, 2017).

\section{Invited topics covered in the special issue}

The call for papers for this special issue, and the topics listed in it, was vetted by several BRE experts across the US and Canada. The 15 enumerated topics in the call for papers are considered significant to contemporary BRE practice. The majority of these topics are covered by articles in this special issue. A discussion of each topic as it is addressed by accepted articles is found below in the general order in which they appear in the body of this special issue (see Table 1). We follow that discussion with a focused literature review for relevant topics that are not covered by the accepted articles.

Table 1. The rationale for the topic and article layout in this issue.

\begin{tabular}{|l|l|}
\hline \multicolumn{1}{|c|}{ Topics covered in the special issue } & \multicolumn{1}{c|}{ Context } \\
\hline The intersection of BRE with economic development & Where does BRE fit in the big picture? \\
\hline Data collection \& moving to implementation & Signature functions of BRE \\
\hline Relationship building \& partnerships & Key elements for success \\
\hline Education for BRE & Building capacity \\
\hline Innovations in BRE \& baby boomer business retention & What's new and promising? \\
\hline Measuring results & What are EDOs measuring and why? \\
\hline Case studies - examples of real BRE programming & State and provincial programs \\
\hline Public policy implications & Implications beyond the community level \\
\hline
\end{tabular}

\section{The intersection of BRE with other economic development strategies and methods}

Two articles directly address how BRE intersects with other economic development strategies and methods, particularly regarding clusters and entrepreneurship. Zhang and Warner (2017) argue that BRE's leading edge today is business cluster development. Their analysis of longitudinal survey data from American cities and a deep literature review lead them to conclude that Michael Porter $(1995,1997)$ was only partially correct with regard to business clusters. They 
argue that clusters are important but that community development practices focusing on quality of life issues are also essential to success. Warren (2017) provides an example of an entrepreneurship-oriented BRE in regional economic development for the Northeast Ohio region that includes Cleveland. Although 65\% of the annual job creation there is tied to BRE, the region has embarked on a strategy focusing on business creation and development in order to achieve and exceed national job creation and per capita income benchmarks.

\section{Data collection methods}

Only one new methodology for basic BRE data collection is discussed in this special issue. Warren (2017) describes the use of the "business model canvas” to gather data from and forge informative connections with entrepreneurs in Northeast Ohio. Warren, as well as Darger et al. (2017), allude to experimentation with new methods of BRE data collection. We hope to see research on these innovations in a future special issue on BRE or the general economic development literature.

\section{Moving from data collection to strategic, systemic action}

This theme discusses how aggregated BRE data leads to action on issues affecting multiple businesses in the EDO jurisdiction. Darger et al. (2017) reported several systemic priority projects reported by Minnesota communities as a direct result of examining their survey data. Templin et al. (2017) also cite an example of business succession programming that resulted from a BRE survey effort. Finally, Morgan and Morphis (2017) provide an example of a "best practice” workforce program in Wayne County, North Carolina, that was originally generated as a direct result of data aggregated from their business visits. 


\section{Relationship building with business}

All BRE efforts are involved to a significant degree in learning about businesses located in an EDO's community or region and developing basic connections with those businesses. To move beyond these basic connections, EDOs need to build relationships with businesses. Two articles explicitly address relationship building. O’Neil et al. (2017) discuss how BRE builds relationships with businesses that lead to four types of follow-up action. They also give examples of fostering business-to-business relationships. Warren (2017) discusses direct relationship building in the context of regional entrepreneurial development.

\section{Broad-based partnerships for BRE}

Enlightened BRE practitioners realize the immense importance, albeit complicated, of broad partnership for BRE success. Four authors stress this theme. Munnich and Douma (2017) describe transportation in a partnership between two state agencies, a university, and local EDOs. O’Neil et al. (2017) provide an example of a private sector partnership between a statewide chamber and local chambers for business assistance. Warren (2017) details the tools used and various partners involved in assessing and providing appropriate assistance to entrepreneurs in a regional context. Finally, Oosterbaan and Morris (2017) observe that collaboration itself is increasingly important for BRE in terms of the outreach to business, the analysis of data, and success in responding to business concerns.

\section{Education and capacity building}

As mentioned in the introduction, BRE education courses have existed for many years. However, only Oosterbaan and Morris (2017) discuss education in terms of methods used to educate and 
orient program coordinators across rural Ontario. We hope to see more research on BRE education in the future.

\section{Innovations in BRE}

Innovation is implicit in all the articles, but three articles provide explicit examples of innovative efforts. First, Bowen-Ellzey and Romich (2017) argue that EDOs should consider the multiple benefits of energy efficiency and renewable energy investments by businesses in terms of both environmental/cost benefits and the potential increased commitment to the location by the business that utilizes these investments. Second, Warren's (2017) illustration of the extension of BRE into entrepreneurial strategies (and vice versa) is an innovative practice. Although the results are still emerging, this innovation is worthy of inclusion in this issue because of the inherent connection of BRE and entrepreneurship focused on homegrown businesses. Third, BRE and state transportation issues are the central theme in Munnich and Douma (2017). Highway and other transportation systems are necessary, but not sufficient conditions, for economic development success. However, the authors make the case that paying attention to major transportation users and manufacturers is a legitimate extension and innovative use of BRE visitation techniques.

\section{Retaining baby boomer businesses in the community}

The baby boomer generation, born between 1946 and 1964 (Colby \& Ortman, 2014), is now in transition to retirement. Businesses owned by this large demographic group represent a key business retention opportunity for economic developers, especially in rural settings. Templin et al. (2017) describe research on business succession in two states in the upper Midwest, including 
community efforts to retain valuable businesses even as the ownership and/or leadership change in those businesses.

\section{Measuring BRE results}

Two articles deal with measuring the results of BRE programming efforts. At the macro level, Morgan and Morphis (2017) examine the process and outcomes dimensions of BRE. They analyze International Economic Development Council (IEDC) survey data from 416 EDOs and present case studies of five EDOs to understand how economic developers are measuring their BRE results. At the individual program level, Darger et al. (2017) describe the evaluation of a statewide BRE program as well as a qualitative analysis method (ripple effect mapping) used to capture the outcomes of volunteer-intensive community BRE initiatives. Both articles also report a generative aspect to BRE (i.e. that BRE analysis can lead to new programs or resources). They provide examples of communities that examined the aggregated data from their business surveys to generate systemic responses to business concerns.

\section{Case studies of BRE results over time}

Three articles cover longitudinal efforts to deliver BRE programming in two states and a Canadian province. O’Neil et al. (2017) estimate a collective impact in terms of the jobs protected in Minnesota as a cumulative result of program efforts. Both of the articles by O’Neil et al. and Darger et al. (2017) provide selected examples of success in terms of business or community level accomplishments. Finally, in a program development or evolution vein, Oosterbaan and Morris (2017) as well as Darger et al. describe efforts to improve institutional BRE programs through the years. 


\section{Public policy implications}

Public policy is implicit in any discussion of BRE that involves the public sector. Thus, in a sense all the articles contained in this issue deal with public policy. One paper explicitly discusses this concept. O’Neil et al. (2017) delve into the information that their state chamber BRE program garners for public policy advocacy at the state and other public entities in Minnesota.

\section{Literature review for BRE topics not covered in submitted articles}

A few topics listed in the call for abstracts were not explicitly discussed in the accepted articles. Since these topics address important BRE issues, a focused literature review was conducted. Topics examined include benchmarking BRE data, implementing quality data collection using technology (i.e. other than the traditional face-to-face interviews), the process of BRE in its various forms, and the issue of using volunteer visitors versus professional economic developers in programming efforts.

\section{Benchmarking BRE data}

The topic of benchmarking data is one that has received scant mention in the published BRE literature. Benchmarking is defined here as "a rigorous yet practical process for measuring your organization's performance and processes against those of best-in-class organizations, both public and private, and then using this analysis to improve services, operations and cost position dramatically" (Bruder \& Gray, 1994, p. S-9). Lenzi (1996) challenged EDOs to focus on the results from their BRE efforts in terms of program outputs (rather than inputs). He suggested combining both public sector and private sector criteria in the benchmark analysis used to evaluate the EDO’s relative success (Lenzi, 1996). In the same vein, Loveridge encouraged 
practitioners to align their survey questions to benchmark their BRE survey data against statewide averages (Loveridge, 1997). More recently, Cothran suggested the preparation of a community assessment as a tool to educate BRE program staff and stakeholders and as a benchmarking tool for the community to be able to understand its relative strengths and weaknesses (Cothran, 2009). Finally, the University of Minnesota Extension Center for Community Vitality shared BRE datasets from 43 Minnesota communities in an online format that allow EDOs to benchmark themselves as well as to see patterns in business survey responses since 1993 (University of Minnesota Extension Center for Community Vitality, 2015).

\section{Quality data collection using technology}

BRE data collection has traditionally been conducted through scripted, in-person interviewing. The rationale for this approach includes collecting high quality data, gaining a higher response rate, and developing relationships with local businesses (Loveridge \& Morse, 1998; Morse, 1990). Some practitioners emphasize the scripted, formal interview, especially when using volunteers to visit businesses (Loveridge \& Morse, 1998) whereas others have emphasized a more conversational approach (O’Neil et al., 2017). However, they all have relied on personal visitation as the preferred method for outreach to businesses. But what other technology is being or could be used to accomplish BRE goals?

When attempting to conduct a very large scale BRE study, a mixed mode survey strategy is often used. For instance, Jagoda, Lin, Calvert, and Tao (2016) used in-person interviews by EDOs as well as mail-out, online, and printed surveys to reach out to rural businesses across the province of Alberta, Canada. With 408 usable surveys out of 1,000 attempts, the researchers were satisfied with the response. Their technique incorporated mixed mode surveying in order to maximize their data collection in 14 communities across the province. 
Mixed methods data collection is increasingly seen in social science. This can include combining focus groups with surveys. Hill and Darger (2014) combined focus group methods with "clicker" survey technology (also known as audience response technology) in a BRE program with the Minnesota city of Columbus. They describe their methods and findings from the use of a time-tested method (focus groups) as well as a newer technology (clickers).

\section{The process of BRE}

No new process methods regarding BRE programs were found in the literature, nor did any of the special issue authors make an issue, per se, of process in their discussion. Nevertheless, the majority of the articles do, to some extent, discuss the processes and methods involved in their specific business retention and expansion activities and programs.

\section{Using volunteer visitors vs. professional economic developers}

Finally, the issue of using volunteers in BRE is a debatable topic for many EDOs. The guest editors have worked with a variety of EDO networks for many years and have observed an increase in reliance on professional staff for business visitation, data collection, and business issue response. While this topic is not easily found in the literature, there was a discussion in a plenary session at the 2016 Annual BREI Conference held in San Marcos, Texas, where only one participant acknowledged using volunteers in programming efforts. The other participants used professional staff for their programming (J. Bennett, personal communication, June 15, 2016). The sole piece of literature found in our abbreviated review is a master's thesis study completed by Parras (2011). Parras found that no EDOs in North Texas were using volunteers. His sample was of five communities ranging in size from 40,474 to 1,200,530. Although the sample size was quite small, his findings are not surprising because mid and large size communities are often 
endowed with one of more full-time economic development staff. Nevertheless, volunteers are still being used in several states or provinces (Minnesota, Ohio, Ontario, New Hampshire, and Oregon to name a few; three of these regions are discussed in this special issue). It is likely that more rural and smaller places are using volunteers whereas larger and/or metropolitan areas seem far less likely to engage in this type of programming effort. Parras notes in his thesis some of the essential factors that EDOs need to be aware if they choose to use volunteers in their BRE programs, such as volunteer recruitment, management, and training.

\section{Summary}

BRE is an enduring part of economic development today. While the articles contained in this issue contribute significantly to the body of research, the guest editors acknowledge that this is not an all-inclusive volume. More research is needed to understand the collective impact of BRE and how it integrates with modern economic development practice. Future research that is particularly desirable includes impacts at the state/provincial level, innovations in practice, process insights, and examples of cooperative data sharing in regional situations.

\section{Acknowledgements}

This special issue of Community Development, an official journal of the Community

Development Society, was made possible by financial and in-kind support provided by Business Retention and Expansion International (BREI), Mississippi State University, The Ohio State University, and University of Minnesota Extension. In-kind support was provided by the National Association of Community Development Extension Professionals (NACDEP), the Community Development Society (CDS), and the International Economic Development Council (IEDC). 


\section{References}

Bowen-Ellzey, N., \& Romich, E. (2017). Energize job retention: Energy management strategies as a component of business retention and expansion programs. Community Development, 48(2), 271-281.

Bradshaw, T., \& Blakely, E. (1999). What are "third-wave” state economic development efforts? From incentives to industrial policy. Economic Development Quarterly, 13(3), 229-244.

Bruder, K., \& Gray, E. (1994). Public sector benchmarking: A practical approach. Public Management(PM), 76(9), S9-14.

Colby, S.L., \& Ortman, J.M. (2014). The baby boom cohort in the United States: 2012 to 2060. Retrieved from https://www.census.gov/prod/2014pubs/p25-1141.pdf

Coleman, B. (1991). Minnesota business retention and expansion program. Economic Development Review, 9(1), 23-25.

Cothran, H.M. (published 2009, reviewed in 2012). Business retention and expansion (BRE) programs: Preparing a community assessment. Retrieved from http://citeseerx.ist.psu.edu/viewdoc/download?doi=10.1.1.631.5263\&rep=rep1\&type=pdf

Darger, M., Tuck, B., \& Bennett, J. (2017). Lessons learned from a generation of communitydriven BRE programming. Community Development, 48(2), 207-224.

Hill, J., \& Darger, M. (2014). Using focus groups for business retention and expansion (BR\&E) at the community level: Detailed notes about the Columbus, Minnesota BR\&E program. University of Minnesota Department of Applied Economics Staff Paper. Retrieved from http://purl.umn.edu/183432 
International Economic Development Council (IEDC). (2015). Economic development reference guide. Retrieved from http://www.iedconline.org/clientuploads/Downloads/IEDC_ED_Reference_Guide.pdf

Jagoda, K., Lin, X., Calvert, V., \& Tao, S. (2016). Accountability of venture support agencies: Do they really help? Entrepreneurship Research Journal, 6(2), 175-206. doi:http://dx.doi.org/10.1515/erj-2014-0038

Lenzi, R.C. (1996). The entrepreneurial community approach to community economic development. Economic Development Review, 14(2), 16.

Loveridge, S. (1997). Guidelines for research reports in business retention and expansion programs. Economic Development Review, 15(1), 3.

Loveridge, S., \& Morse, G.W. (1998). Implementing local business retention and expansion visitation programs (a series of five educational booklets on BRE). College Station, Pennsylvania: Northeast Regional Center for Rural Development at Penn State University. Retrieved from http://www.extension.umn.edu/community/businessretention/strategies/resources-booklets/

Loveridge, S., \& Smith, T.R. (1992). Factors related to success in business retention and expansion programs. Community Development, 23(2), 66-78.

doi:10.1080/15575339209489931

Loveridge, S., \& Smith, T.R. (1992). Fostering partnerships between local governments and rural businesses. Public Productivity \& Management Review, 15(3), 329-340.

doi:10.2307/3380614 
Morgan, J., \& Morphis, C. (2017). Defining success in business retention and expansion: What do economic development organizations measure and why? Community Development, 48(2), 299-316.

Morse, G. (1990). The retention and expansion of existing businesses. Theory and practice in business visitation programs. Ames: Iowa State University Press.

Munnich, L., \& Douma, F. (2017). Obtaining manufacturers’ perspectives in making regional transportation decisions. Community Development, 48(2), 240-254.

O’Neil, S., Schaff, K., \& Riffe, A. (2017). Grow Minnesota!: Using grassroots data to support business growth and retention in the state of Minnesota. Community Development, 48(2), 225-239.

Oosterbaan, C., \& Morris, S. (2017). Increasing capacity of rural clients to access economic development programs: The Ontario BRE case study. Community Development, 48(2), $255-270$.

Pages, E.R., \& Toft, G.S. (2009). Benchmarking innovation. Economic Development Journal, 8(1), 22.

Parras, N. (2011). Business retention programs in North Texas (masters thesis). Retrieved from https://digital.library.txstate.edu/handle/10877/3680

Porter, M.E. (1995). The competitive advantage of the inner city. Harvard Business Review, 73(3), 55-71.

Porter, M.E. (1997). New strategies for inner-city economic development. Economic Development Quarterly, 11(1), 11-27. 
Templin, E., Chazdon, S., Barroso, F., Muske, G., Osborne, L., \& Craig, W. (2017). The silver tsunami and rural small business retention: What can communities do? Community Development, 48(2), 282-298.

University of Minnesota Extension Center for Community Vitality, Business Retention and Expansion Program. (2015). BR\&E Benchmarks. Retrieved from http://www.extension.umn.edu/community/business-retention/researchdevelopment/benchmarks/

Warner, M., \& Zheng, L. (2011). Economic development strategies for recessionary times: Survey results from 2009. The ICMA Municipal Year Book 2011. Washington, D.C.: ICMA, 33-42. Retrieved from http://cms.mildredwarner.org/p/164

Warren, W. (2017). Coordination of entrepreneurial growth methods and business retention and expansion outreach. Community Development, 48(2), 187-206.

Zhang, X., \& Warner, M. (2017). Business retention and expansion and business clusters - A comprehensive approach to community development. Community Development, 48(2), 170-186. 